\title{
Is Supply Chain a complex system?
}

\author{
Safaa Raaidi ${ }^{1 *}$, Imane Bouhaddou ${ }^{1}$, and Asmaa Benghabrit ${ }^{2}$ \\ ${ }^{1}$ LM2I Laboratory, ENSAM, Meknes, Morocco \\ ${ }^{2}$ LMAID Laboratory, ENSMR, Rabat, Morocco
}

\begin{abstract}
Nowadays, industries are continually looking to implement new subsidiaries in different continents, in order to better fulfill their customers' needs, generate the best products in the shortest time and cheaper than their competitors. Achieving these goals is no longer related to the company itself, but to all partners in the supply chain. This justifies the need for efficient and judicious management of the whole supply chain, through the collective intervention of all its actors. Needless to say, a supply chain is a system made up of a set of suppliers, producers, subcontractors, retailers, wholesalers and customers, between whom material, information and financial flows are exchanged. Management of these flows is becoming increasingly difficult and constitutes the main source of the supply chain complexity. In order to alleviate this problem and improve supply chain performance, it is necessary to model it, taking into consideration its characteristics, which make it a complex system. Hence, the scoop of this paper is to prove that supply chain is a complex system, by highlighting its most relevant characteristics that make it such a system. Complex means what is braided together or woven together. If we separate the elements, we get acquaintance elements, but we lose their interactions. Within this trend, our contribution subscribes with its ultimate purpose modelling supply chain as complex system.
\end{abstract}

\section{Introduction}

Open borders to international trade or what is so-called "free trade" proved to be one of the main companies" issues all over the world. Industries are continually looking to implement new subsidiaries in different continents, in order to better fulfill their customers' needs and requirements, generate the best products in the shortest time and cheaper than their competitors. Achieving these goals is no longer related to the functions, activities and processes of the company itself, but to all supply chain partners. This justifies the need for efficient and judicious management of the whole supply chain, through enhanced collaboration between all its actors.

A supply chain is a system made up of a set of suppliers, producers, subcontractors, wholesalers, retailers and customers, between whom material, information and financial flows are exchanged [1]. The management of these flows, particularly the material and information flows, is becoming increasingly difficult and constitutes the main source of the supply chain complexity. In fact, the factors of supply chain complexity have steadily increased in the last decades, namely: the uncertainty, the multiplicity, the variability, the size, the speed, the diversity, etc.

As a matter of fact, nobody can deny that supply chain management is becoming increasingly difficult, we can even say that the supply chain can be seen as a complex system. In fact, in order to propose an efficient and judicious model to reduce this complexity and improve the supply chain performance continually, our contribution consists on showing theoretically this axiom, in the perspective of the complex systems theory.

\section{Supply chain}

There is no universal definition that clarifies the global meaning of the term "supply chain". Some definitions adopt a product point of view and others an "enterprise" or "process" point of view [2]. For example, APICS dictionary defines supply chain as: "The global network used to deliver products and services from raw materials to end customers through engineered flows of information, physical distribution, and cash" [3].

According to Labarthe [4], "Supply chains constitute an economic and social system made up of a set of interacting enterprises, and implementing processes of cooperation, coordination and negotiation in order to ensure their efficiency and durability in satisfying the customer demand".

However, the literature shows that the majority of definitions take up a certain common ideas:

- A supply chain usually refers to finished good or a family of finished goods.

- It involves several companies, several actors.

- These companies are linked by three streams: the information flow, physical flow and financial flows.

* Corresponding author: raaidisafaa@ gmail.com 
- Each stakeholder performs the functions of supply, transformation / production, distribution or sale.

- A company is potentially involved in several supply chains. Indeed, a company generally seeks to multiply its client-companies and its products can be used for the development of several finished products [5].

Within each organization in a supply chain, a participant receives demands from the prior downstream stage and places orders with the next upstream stage to be able to supply the downstream customer demands [6].

Furthermore, some works put more emphasis on the purpose of a supply chain by introducing the notion of performance, this performance being mainly characterized by the satisfaction of the ultimate customer [2]. So as to measure this performance, Michael $H$. Hugos has pointed out in the fourth edition of his guide "Essentials of Supply Chain Management" [7], that companies in any supply chain must make decisions individually and collectively regarding their actions in five areas:

1. Production: this activity includes the creation of master production schedules that take into account plant capacities, workload balancing, quality control, and equipment maintenance.

2. Inventory: the primary purpose of inventory is to act as a buffer against uncertainty in the supply chain. However, holding inventory can be expensive, so what are the optimal inventory levels and recorder points?

3. Location: this activity aims to specify where facilities for production and inventory storage should be located, and choose then the most cost-efficient locations. In order to determine the possible paths available for product to flow through for delivery to the final consumer.

4. Transportation: Airfreight and track delivery are generally fast and reliable mode of inventory transportation from one supply chain to another, but they are expensive. However, shipping by sea or rail is much less expensive but usually involves longer transit times and more uncertainty.

5. Information: with good information, people can make effective decisions about what to produce and how much, about where to locate inventory, and how best to transport it.

In the balance of this paper, we adopt the following definition: "A supply chain is a system consisted of many participants (suppliers, producers, distributors, retailers, customers, etc), which collaborate, directly or indirectly, to fulfil customer demand along the supply chain, through three flows' types: materiel, informational and financial, all the while ensuring supply, transformation, production, distribution, and sale functions". Figure 1 shows an example of the defined supply chain.

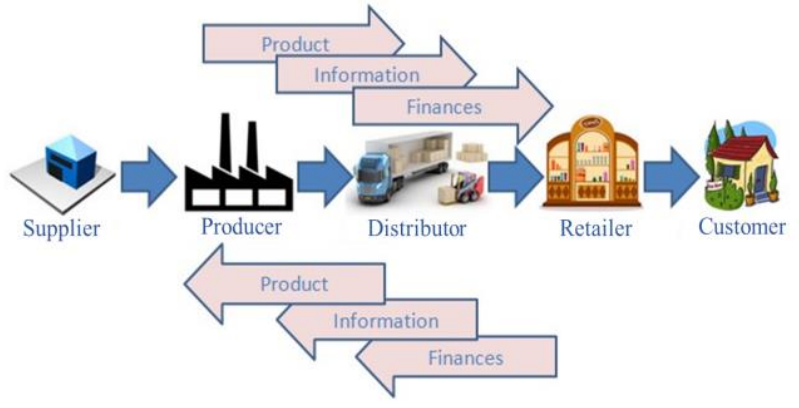

Fig. 1. Example of the defined supply chain.

Nowadays, information flows do not follow this linear form, but rather now look like a simultaneous exchange, as shown in the Figure 2, especially through advanced Information and Communication Techniques (ICT).
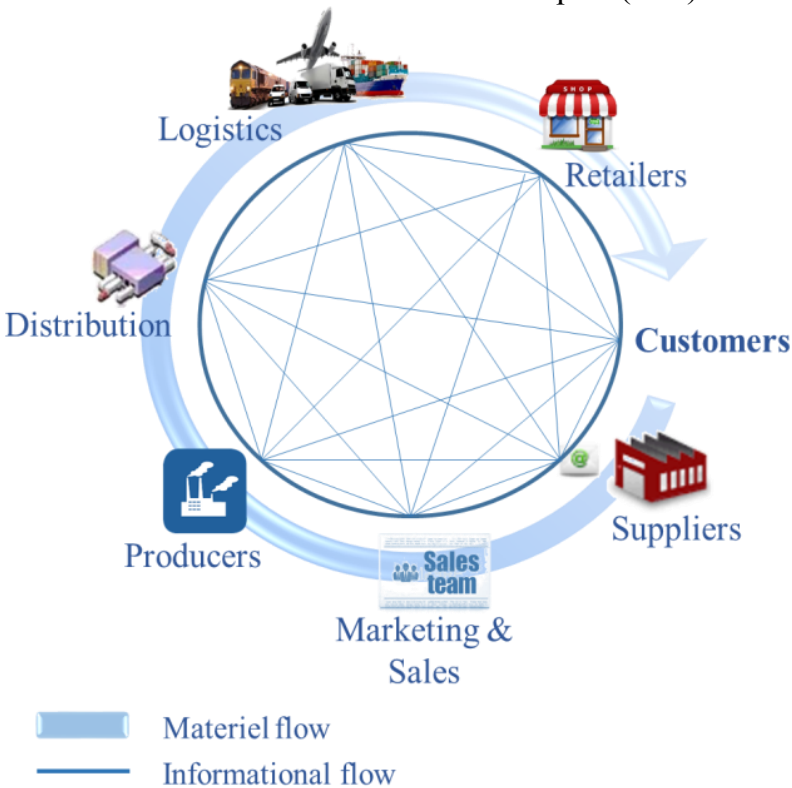

Fig. 2. The new flows distribution within supply chain (Inspired by [1]).

\section{Complex systems}

\subsection{Definition}

In fact, there is no agreement between Scientifics in the field of complex systems about these systems definition. However, there is a number of definitions that contain some similarities. According to E. Morin, who is considered as the father of complex thinking, "Complex comes from complexus, which means what is braided together or woven together" [8], we cannot deduce the overall system functioning by the addition of the subsystems or parts that compose it, because the whole is greater than the sum of its parts. We are therefore talking about the central property of complex systems, which is emergence. Mitchell defines complexity relying, in addition to emergence, on self-organisation:" ...system that exhibits nontrivial emergent and self-organizing behaviors" [9], that is refer to the ability of the 
components of a complex system to create organised behaviour without an internal or external controller [10]. Of course, emergence and self-organization are not the only characteristics of complex systems. We will explain the remaining characteristics in Table 1.

Taking as an example of complex systems, a simple molecule of water. We often hear that "water is life", all living things are mostly composed of water, that is, it contains properties that ensure the living beings life. However, they are found neither in the hydrogen atom nor in the oxygen one.

Nevertheless, Ross and Ashby, both an engineer and a mathematician, defined complexity as "the degree of a system variety". A system is a unit composed of extremely diverse elements. The more varieties a system has, the more complex it is [8], and the more it becomes difficult even impossible to predict its behaviour.

Relying on the last example, to make this system even more complex, for example, we use the glucose molecule that dissolves easily in water. Considering the

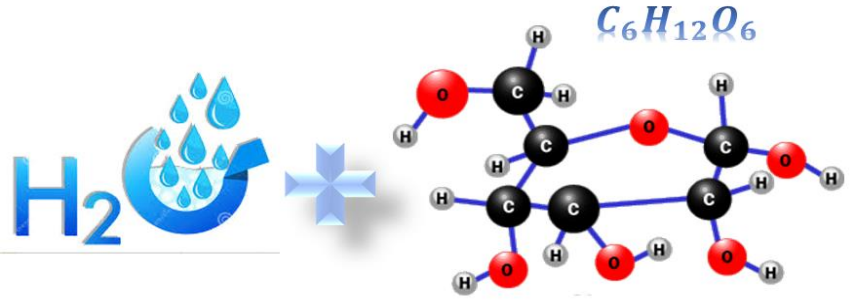

chemical reaction between these two molecules, we get a new system, with more components that are the atoms and more interactions, which generate a more complex system, as shown in the figure 3 .

We then adopt the following definition: "A complex system is a system composed of a set of homogeneous or heterogeneous elements, interacting with each other in a non-linear way, thus implementing a dynamic allowing the whole system to exist as a whole [11].

\subsection{Complex systems characteristics}

Several authors (Filiz Isik, 2011), (Andreas Koch \& Laurent Larsonneur, 2008), (Gezhi Weng et al., 1999), (Le Moigne J.L, 1999) highlight that Complex systems are characterized by multiple properties, (Abla Chaouni et al., 2017) grouped them in article [12], as showing in Table 1.

Fig. 3. Chemical reaction between water $\mathrm{H}_{2} \mathrm{O}$ and glucose $\mathrm{C}_{6} \mathrm{H}_{12} \mathrm{O}_{6}$ is a complex system.

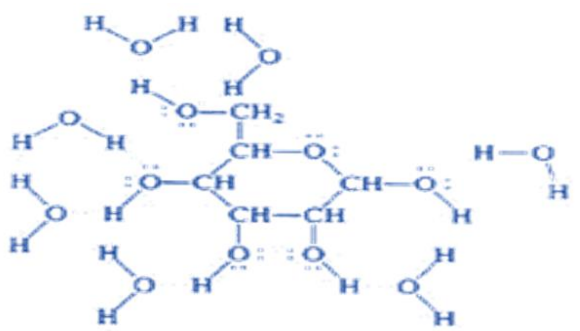

Table 1. Complex system characteristics.

\begin{tabular}{|l||l|}
\hline \multicolumn{1}{|c||}{ Characteristic } & \begin{tabular}{l} 
We talk about emergent behavior when a property appears at the global level, without it \\
being obvious or immediately predictable from the behavior of the elementary constituents \\
of the system [13]. \\
\hline Emergence
\end{tabular} \\
\hline Complexity results from the inter-relationship, inter-action and inter connectivity of the \\
elements within a system and between a system and its environment.
\end{tabular}




\begin{tabular}{|l|l|l} 
Heterogeneity & $\begin{array}{l}\text { The system has different types of elements. The species of a rainforest, people living in } \\
\text { large towns, vendors in malls, structure of the mammalian brain all exhibit extreme } \\
\text { diversity. }\end{array}$ \\
\hline Open & $\begin{array}{l}\text { An open system is a system that has external interactions. Such interactions can take the } \\
\text { form of information, energy, or material transfers into or out of the system boundary, } \\
\text { depending on the discipline, which defines the concept. }\end{array}$ \\
\hline Complex systems can change their internal structure in response to changes in their \\
environment; this ability allows them to survive but also to learn [13].
\end{tabular}

\section{Supply chain complexity}

The management of material and information flows, along the supply chain system, is becoming increasingly difficult and constitutes the main source of the supply chain complexity. In fact, the supply chain complexity factors have been steadily increasing in recent decades, Table 2 summarizes the most influential factors in the supply chain.

Supply chain complexity can be defined as quantitative differences between predicted and actual states, which are associated with uncertainty and/or variety caused by internal and external drivers in a supply chain system [6].

Table 2. Supply chain complexity factors.

\begin{tabular}{|c|c|}
\hline Uncertainty & $\begin{array}{l}\text { Galbraith defines uncertainty in [14], as the difference between the amount of information needed to } \\
\text { perform a task and the amount of information that is already available. The uncertainty sources within } \\
\text { supply chains are multiple, namely: uncertainty about deadlines, customer demand, processes, } \\
\text { markets, etc. }\end{array}$ \\
\hline Multiplicity & $\begin{array}{l}\text { This characteristic of the complexity covers the number of components such as items (raw, } \\
\text { manufactured or end), products, processes, stakeholders, relationships, interactions, goals, locations, } \\
\text { etc. A high number level of any components contributes increasingly complexity in a supply chain } \\
\text { system [6]. }\end{array}$ \\
\hline Variability & $\begin{array}{l}\text { Consists of elements or components, which are different from each other. It represents dynamical } \\
\text { behaviour of a system [6]. }\end{array}$ \\
\hline Size & $\begin{array}{l}\text { Industries are continually seeking to implement new subsidiaries in the various continents, in order to } \\
\text { better meet their customers' requirements, to find new markets and new customers. As a result, supply } \\
\text { chain becomes more extensive, its product lines become more diversified and the number of its } \\
\text { processes multiplies. }\end{array}$ \\
\hline Speed & $\begin{array}{l}\text { The production speed is becoming higher, and product life cycles are becoming shorter, especially } \\
\text { with advanced information and communication technologies, which constitute one of the main } \\
\text { concerns for any company to survive and increase in the market. }\end{array}$ \\
\hline Diversity & $\begin{array}{l}\text { Related with the homogeneity or heterogeneity of a system. For example: A high level of diversity of } \\
\text { any components (supplier, product, mean of transport) along the supply chain leads to system's } \\
\text { heterogeneity and results a high level of complexity [15]. }\end{array}$ \\
\hline
\end{tabular}

Complexity has many negative consequences on supply chains such as high operational costs, customer dissatisfaction, time delay in delivery, excess inventory or inventory shortage, lack of cooperation, collaboration and integration among supply chain participants, etc [6]. Confronted with such daunting complexity, supply chain executives reported that they face five major challenges, as shown in Figure 4 [16]. According to IBM Global Services, the most critical challenge that has the very significant impact on supply chain is "Supply chain visibility" with $70 \%$, then "Risk management" with 60\%, "Increasing customer demands" with $56 \%$, "Cost containment" with 55\%, and ultimately "Globalization" with $43 \%$.

All are critically important, and must be addressed simultaneously. Together, they comprise what we call the Chief Supply Chain Officer agenda [16].
To overcome this problem of supply chain complexity and continuously improve its performance, it is necessary to model it. Indeed, researchers were proactive in the modeling of the supply chain (for example: by multi-agent systems, the SCOR model, mathematical models). However, our approach aims to model it in a complex perspective, taking into account its characteristics that make it a complex system. This correspondence will be the subject of the following section.

\section{Supply chain as complex system}

In the light of all these definitions and complex systems' characteristics, we will deduce that the supply chain is a complex system, as result of taking exactly these same characteristics. The detail of this correspondence is summarized in Table 3 . 


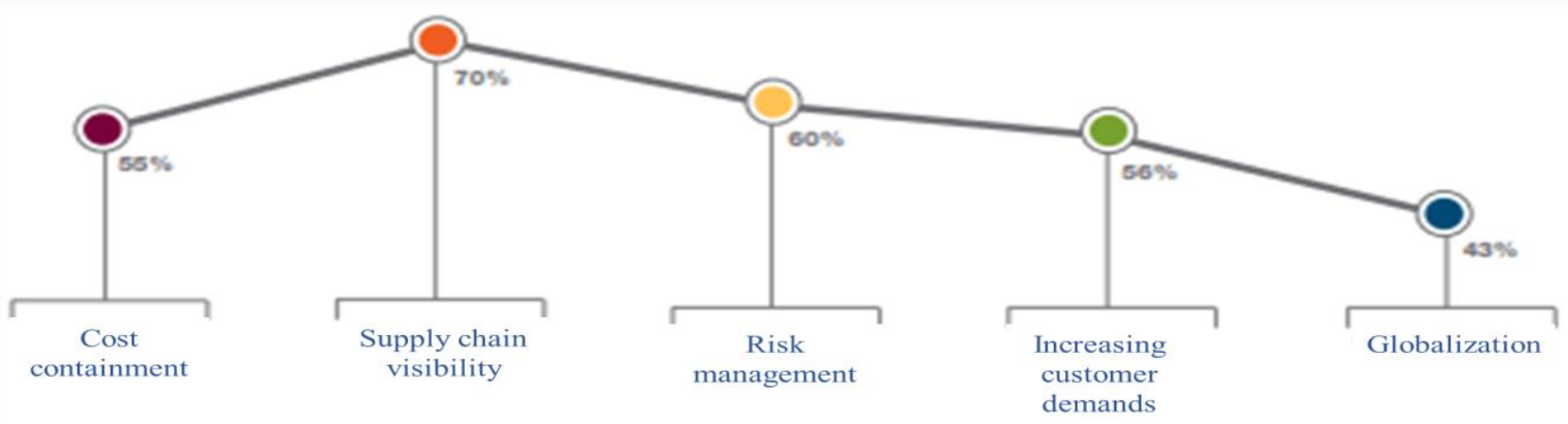

Fig. 4. Supply chain leaders wrestle with five major challenges [16].

Table 3. Supply chain as complex system.

\begin{tabular}{|c|c|}
\hline Characteristic & Projection on supply chain \\
\hline Emergence & $\begin{array}{l}\text { The manufacture of a finished good, or even a semi-finished product, imperatively requires } \\
\text { the collaboration of several supply chain entities. Therefore, the supply chain cannot be } \\
\text { reduced to a single entity, but rather it is considered as a whole. For instance, when the } \\
\text { company makes a product, it will be beneficial to deliver it to its customer right after its } \\
\text { manufacture, in order to avoid the additional costs of storage. However, it is not always the } \\
\text { case, because the delivery time represents a compromise between the supplier and each of } \\
\text { its customers, who take, in turn, their customers in their decision-making process, and so } \\
\text { on. Hence, each entity performs its function in collaboration with the other entities, which } \\
\text { generates a collective behaviour. }\end{array}$ \\
\hline Connectivity & $\begin{array}{l}\text { Communication is one of the main keys to supply chain management. It allows obtaining } \\
\text { from all its actors the information and the knowledge, which will favor the course of the } \\
\text { current activities of the company. Especially with advanced information and } \\
\text { communication techniques, which ensure faster and more timely information sharing. }\end{array}$ \\
\hline Co-evolution & $\begin{array}{l}\text { Each peer of (client, supplier) companies co-evolves in parallel, as the supplier company } \\
\text { adapts its strategies and processes according to its customer requirements on the one hand, } \\
\text { and on the other hand according to the evolution of its environment. In the field of smart } \\
\text { phone manufacturing for example, it is remarkable that competition is fierce and life cycles } \\
\text { are becoming even shorter, because of the speed of technological development. To face } \\
\text { this challenge, supply chain partners must innovate continuously, and afterwards they } \\
\text { accept and adapt with the innovative proposals of each of them, in order to co-evolve and } \\
\text { survive in a hyper-competitive environment. }\end{array}$ \\
\hline Distribution control & $\begin{array}{l}\text { The actors of the current supply chains are geo-distributed. Therefore, supply chains } \\
\text { exploit remote control systems, made up of several controllers that control the subsystems } \\
\text { or units of the global installation. Hence, remote control systems ensure a reduction of } \\
\text { uncertainty and improve the entire chain performance. }\end{array}$ \\
\hline Non-linearity & $\begin{array}{l}\text { The non-linearity within supply chains is revealed in the activities, processes, orders, flows } \\
\text { and objectives of the different actors. For example, Bullwhip effect illustrates that a slight } \\
\text { variation in the initial state of the system, generate a significant deviation from its usual } \\
\text { progress. }\end{array}$ \\
\hline State of paradox & $\begin{array}{l}\text { To generate better quality products, the company has to invest even more and take the time } \\
\text { needed to control the product quality. However, the high speed of global progress requires } \\
\text { deliveries in the shortest possible time with optimal costs, compared to competitors. In } \\
\text { addition, the companies are continually seeking to find a compromise between the piloting } \\
\text { system by forecasts, and those by stock. }\end{array}$ \\
\hline Far-from-equilibrium & $\begin{array}{l}\text { Delays in delivery, stakeouts, unexpected breakdowns, fluctuations in demand, etc, are the } \\
\text { main sources of imbalance in the supply chain. }\end{array}$ \\
\hline Heterogeneity & $\begin{array}{l}\text { The supply chain is composed of several participants (suppliers, factories, warehouses, } \\
\text { distributors, wholesalers, etc.), concerns different types of products, relies on several } \\
\text { functions, and uses different processes according to each actor activities. }\end{array}$ \\
\hline
\end{tabular}

*Corresponding author: raaidisafaa@gmail.com 


\begin{tabular}{|l|l}
\hline Open & $\begin{array}{l}\text { Supply chain is an open system that constantly interacts with its environment, it is often } \\
\text { found that an actor is part of several supply chains, on the other hand, the supply chain } \\
\text { involves several suppliers, producers, warehouses, distributors, wholesalers, etc. }\end{array}$ \\
\hline Self-organization & $\begin{array}{l}\text { Supply chain actors can modify their internal strategies in response to the market changes } \\
\text { and its dynamism, to survive in the market and to ensure customer satisfaction. Sometimes } \\
\text { suppliers fail to deliver the products at the right time, or the quantity delivered is not } \\
\text { always of good quality. Then the company must manage this problem in order to ensure its } \\
\text { customer's satisfaction, by providing a stock of risk management even if it can be } \\
\text { expensive for her (hybrid strategy). Thus, the company self-organizes in front of the } \\
\text { market dynamism. }\end{array}$
\end{tabular}

\section{Conclusion}

The globalization of markets and the opening of borders have greatly complicated the supply chain management. Good management of supply chain complexity has become the major concern of any company, in order to remain competitive in the market and better meet its customer's needs.

In this context, our contribution objective is to integrate the two scientific disciplines: that of Supply chain management with the Complex systems field. In this article, we presented a literary overview on the supply chains, explaining its different actors, flows and the main sources of its complexity that hinder its improvement. Then, we have showed a state of art of complex systems, and we have explained all of its characteristics, in order to, theoretically, justify that the supply chain is indeed a complex system because it takes exactly the same characteristics.

As we have already mentioned, to manage the supply chain complexity, it is necessary to model it in a complex perspective, which will be the subject of our next contribution.

\section{References}

1. I. Bouhaddou. Vers une optimisation de la chaîne logistique : Proposition de modèles conceptuels basés sur le PLM (Product Lifecycle Management). Autre [cs.OH]. Université du Havre, 26,31 (2015). Français.

2. FA. Gruata La Forme-Chretien. Référentiel d'évaluation de la performance d'une chaîne logistique - Application à une entreprise de l'ameublement. Lyon : s.n., 28 (2007).
3. American Production and Inventory Control Society. [En ligne] 2001. http://www.apics.org.

4. O. Labarthe. Modélisation et simulation orientées agents de chaines logistiques dans un contexte de personnalisation de masse: Modèle et cadre méthodologique. Marseille : s.n., 26 (2006).

5. J. Francois. Planification des chaînes logistiques : modélisation du système décisionnel et performance. (2008).

6. F. Isik. Complexity in Supply Chains: A New Approach to Quantitative Measurement of the SupplyChain-Complexity. Supply Chain Management, Dr. pengzhong $\mathrm{Li}$ (Ed.), ISBN: 978-953-307-184-8, InTech. (2011).

7. H. Michael. Essentials of Supply Chain Management. s.l. : Wiley, 5,6 (2018).

8. E. Morin. La complexité: un défi à la connaissance. s.l. : L'actualité Poitou-Charentes, $\mathrm{N}^{\circ} 68$, (2004).

9. M. Mitchell. Complexity: A Guided Tour. s.l.: Oxford University Press, (2009).

10. B. Young. Complex Systems Engineering Applications for Future BMC2. Alexendria,VA: ICCRTS, 032 (2013).

11. S. Hassas. Systèmes Complexes à base de MultiAgents Situés. Lyon 1 : s.n., 11,12 (2003).

12. A. C. Benabdellah, A. Benghabrit, I. Bouhaddou Supply Chain Challenges with Complex Adaptive System Perspective. Springer, Cham, 1085,1086 (2018).

13. H. Zwirn. Systèmes complexes (Les): Mathématiques et biologie. 224 (2006).

14. J. Galbraith. Designing complex organizations. Addison-Wesley, Massachusetts. (1973).

15. I. Bouhaddou, A. Benabdelhafid. PLM (Product Lifecycle Management): a key to manage supply chain complexity. CS-DC'15 World e-conference. (2016).

16. IBM Global Services. The smarter supply chain of the future. U.S.A.: s.n., (2009). 